\title{
Comparison of Some Physical and Physiological Parameters of Elite Long-Distance Runners and Cross-Country Skiers
}

\author{
Mehmet GÖKTEPE \\ University of Bartın, Bartın, Turkey \\ Hayri AYDOĞAN \\ University of Recep Tayyip Erdoğan, Rize, Turkey
}

\begin{abstract}
This study aims to determine and compare some physical and physiological parameters of elite long-distance runners and cross-country skiers. The research group consists of 17 male and 13 female athletic long-distance runners and 14 male and 11 female cross-country skiers, all of who are living in Ağrı and are at international level. Wingate test standardizing method and materials were used to measure weight and height to make body composition analysis, breathing function tests, flexibility tests, and to determine anaerobic capacity of the subjects who participated in the research. Statistical evaluation was performed using Statistics Package for Social Science, Version 22.0 (SPSS 22.0) package program. Considering the small number of subjects in the study group $(N<30)$, Mann Whitney $U$ test, which is mainly used for non-parametric data, was used to determine differences between variables. It has been understood that anaerobic capacities and flexibility values of athletes who participated in the study group did not differ significantly $(p>0.05)$. Although there were no significant differences between breathing parameters $(p>0.05)$ in general, there was a significant difference between the breathing values forced expiratory volume 1.0/ forced vital capacity (FEV1/FVC) of female athletes and female cross-country skiers $(p<$ $0.05)$. Body composition values of the athletes did not display any significant differences $(p>0.05)$. However, it was understood that there was significant differences on fat weight $(\mathrm{FW})$ and total body water percentage (TBW[\%]) values between athletes and female cross-country skiers $(p<0.05)$. Gripping power of male athletes and cross-country skiers displayed statistically significant differences for right hand and left hand gripping power $(p<$ $0.05)$, yet it was understood that gripping power of female athletes and cross-country skiers did not differ significantly between their right hands and left hands $(p>0.05)$. As a result of the study, following the comparison of physical and physiological parameters of male and female athletes and cross-country skiers, FEV1/FVC among breathing parameters and $\mathrm{FW}$ and TBW(\%) among body composition values displayed significant differences, and right hand and left hand gripping power of male athletes also displayed significant differences. In this context, it might be concluded that there are not many differences between similar branches of sports (long-distance running, individual sports, etc.) which utilize same energy systems in the body.
\end{abstract}

Keywords: long-distance runners, cross-country skiers, anaerobiccapacity, breathing parameters, gripping power, flexibility

Mehmet GÖKTEPE, Dr., associate professor, School of Physical Education and Sports, Bartın University. Hayri AYDOĞAN, Dr., associate professor, School of Physical Education and Sports, Recep Tayyip Erdoğan University. 


\section{Introduction}

Professional athletes have a luxury of training everyday. However other athletes barely have the chance for training due to constraints in their business, family, and social lives. Some days we are able to work our body only for 20 minutes, whereas some days we have time for more than two hours of training. If you run everyday, you might have a very good aerobic structure, while you might have a weak condition for skiing (Sahin, 2011). Cross-country skiing is a winter sport performed using a ski, shoes, and poles across the world regions which have thick snow. This branch of sports is prevalent in regions with harsh winters such as Northern Europe, Canada, Alaska, and America, but nowadays it is even possible to do this sport indoors, which is called skiing tunnels (Norstrud, 2008; Spring, 2002). Cross-country skiing, which was first performed in early ages for being able to carry out vital duties, such as walking, hunting, and fighting on snowy terrains, is nowadays not only an olympics game, but also a game for children and considered leisure and a way to be with nature and exercise for adults, which is very important to maintain a healthy life (Rusko, 2003). Cross-country skiing is a sport based on endurance and it has a great variety of distances (one to $50 \mathrm{~km}$ ). For that reason, certain physical attributes are required to achieve and maintain the required physical power for this sport (Stöggl, Enqvist, Müller, \& Holmberg, 2010). However, cross-country skiing athletes do not have perfect bodies as swimmers, long-distance runners, or canoers. The most important reason behind this is the variety of requirements for being able to ski on different terrains and at different distances (Çetin, 2002). Long-distance running is the branch of sports which requires the highest stamina and has the thoughest training period. It is a race in which sprinting before the finish line is not important in medium distance and success widely depends on your tempo and stamina. Style and breathing is really important in Long-distance running. Athletes should breath in and out once in two meters. Steps are shorter, yet loose, and feet should touch the ground. Due to the fact that steps are taken like machinery work, it is also called "Car Running." Long-distance races are held between 6,000 meters to 42,195 meters (marathon) based on age groups of participants, parkour, and terrain conditions. Pace, technic, tactic, condition, and stamina are of vital importance for success (Tanner \& Gore, 2013). Considering the fact that both branches are performed under tough conditions, we might suggest that physiological attributes are of significant importance for both.

There is a variety of researches conducted in order to better understand the physical and physiological attributes of athletes, which significantly contribute to the development of activities produced by the science of training. Achieveing success is available through emergence of positive effects of trainings (Savucu, Polat, \& Biçer, 2005). In branches, such as skiing and athletics, determining the differences in terms of some physical and physiological attributes might be significant in terms of branch-specific studies (Bayraktar, Deliceoğlu, Yaman, \& Yaman, 2012). Being successful either in long-distance running or cross-country skiing is important, just like any other sports. In this context, a great variety of parameters, such as structures of contests, training types, and physical, physiological, and motoric abilities of athletes are considered as astonishing subjects for studies on this field.

This study, conducted with the participation of elite long-distance runners and cross-country skiers, aims to determine some physical and physiological parameters of athletes and make comparisons among them.

\section{Material and Method}

In this study, there are 17 male and 13 female long-distance runners and 14 male and 11 female 
cross-country skiers, all of who are living in Ağrı and did not undergo any surgical interventions within one year. All subjects filled in a health status form, which were used to determine their health condition, and a voluntary participation form, which was used to receive their written consent before participating in this study. Context of the study was briefed to participants, with all details. Before the measurements were done, all the participants were warned about alcohol consumption and not exhausting themselves with heavy training a day before the study. Subjects underwent the following measurements, respectively: Height and weight measurement, body composition analysis, and evaluation of breathing parameters. Then, all the subjects underwent a warm-up run for five minutes, and finally, Wingate anaerobic test was done. This study was carried out in Physiology Laboratories of Ağrı İbrahim Çeçen University, Physical Education and Sports Academy.

\section{Height and Weight Measurement}

Height of the subjects was measured with $0.01 \mathrm{~m}$ sensitive (SECA, Germany) stadiometer and weight of the subjects was measured with $0.1 \mathrm{~kg}$ sensitive electronic scale (SECA, Germany) (Köklü, Özkan, Alemdaroğlu, \& Ersöz, 2009).

\section{Body Mass Index (BMI)}

BMI is calculated by dividing the body mass values of subjects to the square of their height measurement values $\left(\mathrm{kg} / \mathrm{m}^{2}\right)$ (Norris et al., 2005).

\section{Determining Body Composition}

Body composition of the subjects was measured using Bodystat ${ }^{\circledR} 1500$ bio-impedance device (Bodystat Ltd, Douglas, Isle of Man, UK) and bio-electric impedance analysis (BIA). BIA is a method in which an electric current at a very low level $(500 \mu \mathrm{A}-800 \mu \mathrm{A})$ is sent to the body at $50 \mathrm{kHz}$ speed and the electric resistance of the body towards this current is measured (Karakaş, 2012). By using the impedance value of the body, following attributes are calculated using simple mathematical formulas: fat percentage, fat amount, lean body percentage, lean body mass, liquid percentage of the body, liquid amount of the body (Sifil et al. 2001; Url, 2016). For proper measurement, attention must be paid to the following issues: 1. Subjects must refrain from eating and drinking four hours before the measurements; 2 . There should be no urines before the bladder; 3 . No alcohol should be consumed 48 hours before the measurements; and 4. Diurethicals must not be used (Öncü, 2009).

\section{Determining Breathing Parameters}

Forced vital capacity (FVC), forced expiratory volüme (FEV1), forced expiratory volüme 1.0 seconds/forced vital capacity (FEV1/FVC), peak expiratory flow (PEF), forced expiratory flow (\% 25-75) (FEF25-75), vital capacity (VC), tidal volume (TV), and maximal voluntary ventilation (MVV) values of the people who participated in the research were measured using breathing function tests (Spirolab II, Medical International Research, Rome, Italy). All of the measurements were conducted by measuring the breath of the subject (in and out) through connecting him to the spirometer, and after an adjustment period, while he was sitting and his nose was covered with a clamp. Each measurement was repeated for three times and the highest values were recorded (Fox \& Mathews, 1976; Kürkçü \& Gökhan, 2011; Alpay, Altuğ, \& Hazar, 2007).

\section{Determining Anaerobic Capacity}

In order to determine the anaerobic capacity of subjects, Wingate Anaerobic Power Test was used in this study. A computer mechanism attached to Monark 834E model bicycle ergometer with scales was used for the test. Before starting the test, blood samples were received from the research group in order to measure rested 
lactic acid values and research group was provided with information related to tests. Research group underwent a standard warm-up consisting of six minutes of exercise on the bicycle ergometer at 140-150 heartbeat/minute and two minutes of stretching exercises (Gökbel, Çalışkan, Özbay, \& Bediz, 1993). Saddle height of the bicycle was adjusted for each individual and $7.5 \%$ (per each $\mathrm{kg}$ ) of their total body weight was placed on the scale of the bicycle. Individuals in the research group pedalled as fast as they can without standing up on the saddle. Supervisor removed the weight on the scale after the maximum speed was reached and the test commenced. Individuals in the research group were verbally motivated after 10-15 seconds. Following the Wingate test, the highest power demonstrated by the athletes was recorded as "peak power" (PP), the average power demonstrated by the athlete was recorded as "average power" (AP), and the minimum power demonstrated by the athlete was recorded as "minimum power" (MP). As a result of 30 seconds of performance in total, fatigue index (FI) was calculated using the formula below:

\section{PP-MP}

$\mathrm{FI}=\ldots$ × 100 (Inbar, Bar-Or, \& Skinner, 1996)

PP

\section{Data Analysis}

Statistical evaluation was performed using SPSS 22.0 program. Data collected during this research were presented in mean average terms and with standard deviations. Considering the amount of participants in the study group $(N<30)$, Mann Whitney $U$ test, which is mainly used for non-parametric data, was used to determine differences between variables (Büyüköztürk, 2009).

\section{Findings}

Age, height, weight, BMI, and sports experience of participants are provided in Table 1. According to the results obtained, the following parameters were collected: For male athletes $19.29 \pm 3.35$ years of age, $175.59 \pm$ $6.72 \mathrm{~cm}$ of height, $65.78 \pm 9.64 \mathrm{~kg}$ of weight, $21.29 \pm 2.53\left(\mathrm{~kg} / \mathrm{m}^{2}\right)$ of BMI, and $6.65 \pm 4.05$ of sports experience (professional); For female athletes $17.85 \pm 2.67$ years of age, $164.23 \pm 4.95 \mathrm{~cm}$ of height, $53.32 \pm$ $7.21 \mathrm{~kg}$ of weight, $19.72 \pm 2.14\left(\mathrm{~kg} / \mathrm{m}^{2}\right)$ of BMI, and $4.08 \pm 2.10$ of sports experience (professional); For male skiers $18.64 \pm 3.59$ years of age, $174.57 \pm 11.02 \mathrm{~cm}$ of height, $66.02 \pm 17.57 \mathrm{~kg}$ of body weight, $21.37 \pm 4.07$ $\left(\mathrm{kg} / \mathrm{m}^{2}\right)$ of weight, and $5.93 \pm 3.75$ years of sports experience (professional); For female skiers $17.91 \pm 2.84$ years of age, $161.27 \pm 6.05 \mathrm{~cm}$ of height, $57.89 \pm 6.32 \mathrm{~kg}$ of weight, $22.23 \pm 1.86\left(\mathrm{~kg} / \mathrm{m}^{2}\right)$ of body mass, and $5.09 \pm 2.95$ years of sports experience (professional).

Table 1

Physical Attributes of the Athletes Who Participated in the Research

\begin{tabular}{llllllll}
\hline Branch & Gender & $N$ & $\begin{array}{l}\text { Age }(\text { years }) \\
(\text { Mean } \pm S D)\end{array}$ & $\begin{array}{l}\text { Body weight }(\mathrm{kg}) \\
(\text { Mean } \pm S D)\end{array}$ & $\begin{array}{l}\text { Height }(\mathrm{cm}) \\
(\text { Mean } \pm S D)\end{array}$ & $\begin{array}{l}\text { BMI }\left(\mathrm{kg} / \mathrm{m}^{2}\right) \\
(\text { Mean } \pm S D)\end{array}$ & $\begin{array}{l}\text { Sports experience } \\
(\text { years }) \\
(\text { Mean } \pm S D)\end{array}$ \\
\hline \multirow{2}{*}{ Athletics } & $\mathrm{M}$ & 17 & $19.29 \pm 3.35$ & $65.78 \pm 9.64$ & $175.59 \pm 6.72$ & $21.29 \pm 2.53$ & $6.65 \pm 4.05$ \\
& $\mathrm{~F}$ & 13 & $17.85 \pm 2.67$ & $53.32 \pm 7.21$ & $164.23 \pm 4.95$ & $19.72 \pm 2.14$ & $4.08 \pm 2.10$ \\
Skiing & $\mathrm{M}$ & 14 & $18.64 \pm 3.59$ & $66.02 \pm 17.57$ & $174.57 \pm 11.02$ & $21.37 \pm 4.07$ & $5.93 \pm 3.75$ \\
& $\mathrm{~F}$ & 11 & $17.91 \pm 2.84$ & $57.89 \pm 6.32$ & $161.27 \pm 6.05$ & $22.23 \pm 1.86$ & $5.09 \pm 2.95$ \\
\hline
\end{tabular}

According to the results related to breathing parameters of sportsmen listed in Table 2, there were no significant differences in terms of breathing parameters, FVC, FEV1, PEF, FEF25-75, VC, TV, and MVV, of 
athletes and skiers, both males and females $(p>0.05)$. There were no significant differences between breathing parameters (FEV1/FVC) of male athletes and skiers. However, breathing parameters (FEV1/FVC) of female athletes and skiers were found to have significant statistical differences $(p<0.05)$.

Table 2

Results of Mann Whitney U Test Conducted to Determine the Significance of the Difference Between Breathing Parameters of Athletes and Skiers

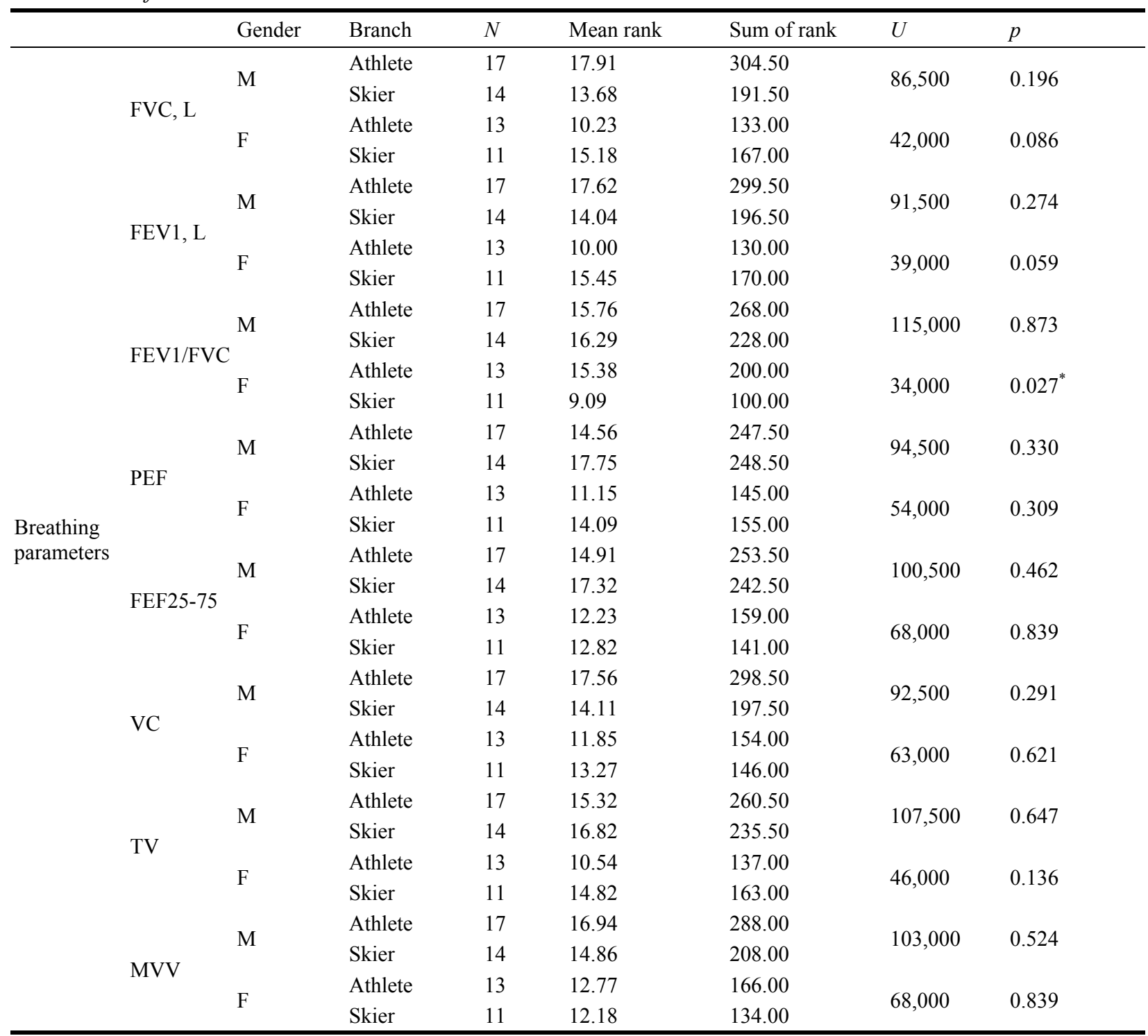

Note. ${ }^{*} p<0.05$.

Results of Mann Whitney $U$ Test, which was conducted to detect the significance of difference between body composition values of athletes and skiers, are provided in Table 3. There were no significant differences $(p>0.05)$ in the following body composition values of male athletes and skiers: FAT (\%) for body fat percentage; FW (kg), fat amount; L (kg),lean mass; DLM (kg), dry lean mass; TBW (\%), total body water percentage; TBW (lt), total body water; and BMR, basal metabolic rate. Similarly, there were no significant 
differences $(p>0.05)$ in the following body composition values of female athletes and skiers: FAT, L, DLM, TBW, BMR. However, it has been understood that FW and TBW body composition values of female athletes and skiers have significant differences $(p<0.05)$.

Table 3

Results of Mann Whitney U Test Conducted to Determine the Significance of the Difference Between Body Composition Values of Athletes and Skiers

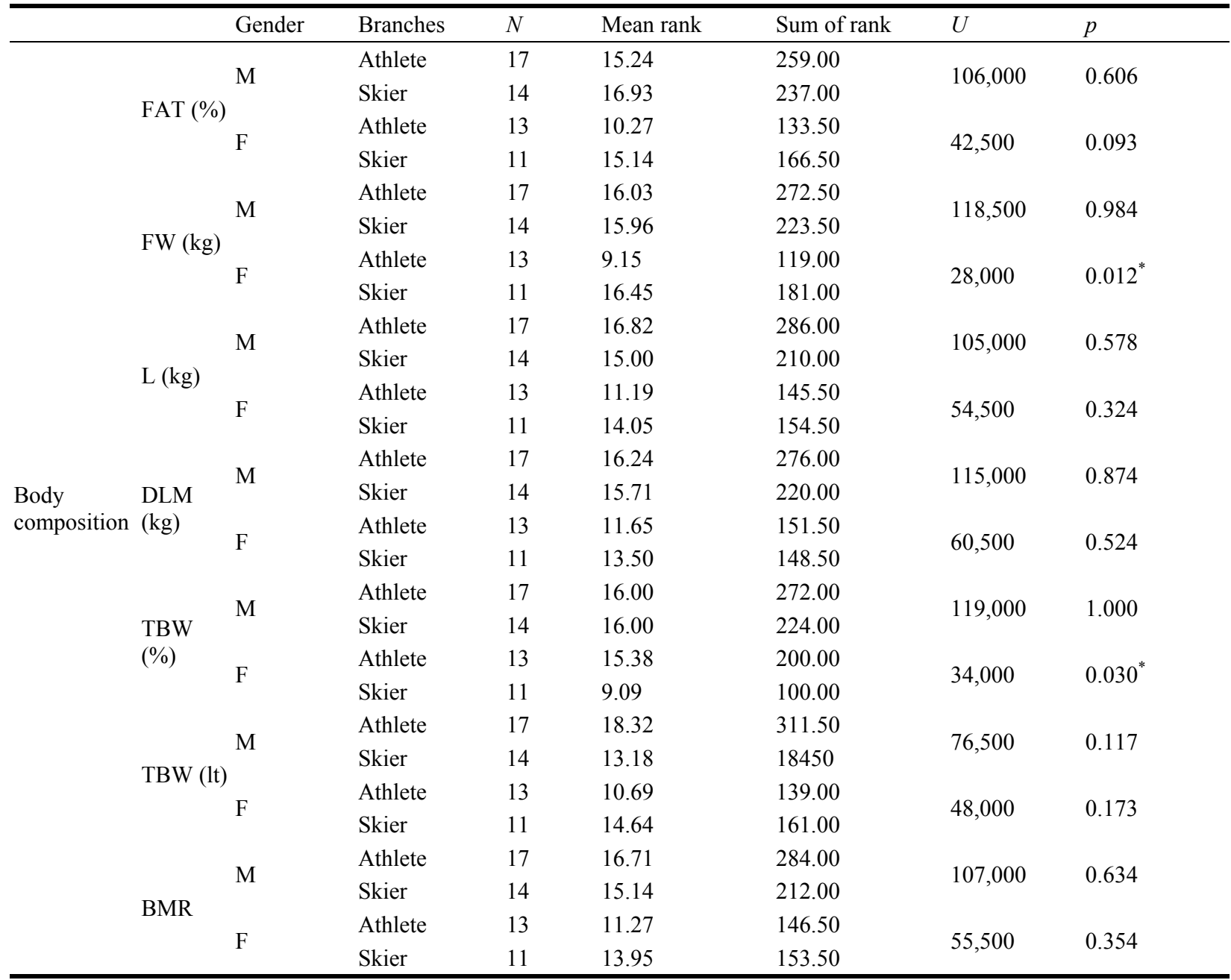

Note. ${ }^{*} p<0.05$.

Results of Mann Whitney $U$ Test, which was conducted to detect the significance of differences between anaerobic capacities of athletes and skiers, are provided in Table 4. According to Table 4, there are no significant differences in terms of PP, AP, MP, and FI among females and males $(p>0.05)$.

Results of Mann Whitney $U$ Test, which was conducted to detect the significance of difference between gripping power of athletes and skiers, are provided in Table 5. According to Table 5, it is understood that there are significant differences between right hand and left hand gripping power values of male athletes and skiers $(p<0.05)$. Considering the values provided on Table 5, it is understood that there are no significant differences between the right and left hand gripping power values of female athletes and skiers $(p>0.05)$. 
Table 4

Results of Mann Whitney U Test Conducted to Determine the Significance of the Difference between Anaerobic Capacity Values of Athletes and Skiers

\begin{tabular}{|c|c|c|c|c|c|c|c|c|}
\hline & & Gender & Branch & $N$ & Mean rank & Sum of rank & $U$ & $p$ \\
\hline \multirow{16}{*}{$\begin{array}{l}\text { Anaerobic } \\
\text { capacity }\end{array}$} & \multirow{4}{*}{ PP } & \multirow{2}{*}{ M } & Athlete & 17 & 17.41 & 296.00 & \multirow{2}{*}{95,000} & \multirow{2}{*}{0.340} \\
\hline & & & Skier & 14 & 14.29 & 200.00 & & \\
\hline & & \multirow{2}{*}{$\mathrm{F}$} & Athlete & 13 & 13.69 & 178.00 & \multirow{2}{*}{56,000} & \multirow{2}{*}{0.369} \\
\hline & & & Skier & 11 & 11.09 & 122.00 & & \\
\hline & \multirow{4}{*}{$\mathrm{AP}$} & \multirow{2}{*}{ M } & Athlete & 17 & 16.82 & 286.00 & \multirow{2}{*}{105,000} & \multirow{2}{*}{0.578} \\
\hline & & & Skier & 14 & 15.00 & 210,00 & & \\
\hline & & \multirow{2}{*}{$\mathrm{F}$} & Athlete & 13 & 12.38 & 161.00 & \multirow{2}{*}{70,000} & \multirow{2}{*}{0.931} \\
\hline & & & Skier & 11 & 12.64 & 139.00 & & \\
\hline & \multirow{4}{*}{ MP } & \multirow{2}{*}{ M } & Athlete & 17 & 15.00 & 255.00 & \multirow{2}{*}{102,000} & \multirow{2}{*}{0.499} \\
\hline & & & Skier & 14 & 17.21 & 241.00 & & \\
\hline & & \multirow{2}{*}{$\mathrm{F}$} & Athlete & 13 & 13.31 & 173.00 & \multirow{2}{*}{61,000} & \multirow{2}{*}{0.543} \\
\hline & & & Skier & 11 & 11.55 & 127.00 & & \\
\hline & \multirow{4}{*}{ Yİ } & \multirow{2}{*}{ M } & Athlete & 17 & 16.76 & 285.00 & \multirow{2}{*}{106,000} & \multirow{2}{*}{0.605} \\
\hline & & & Skier & 14 & 15.07 & 211.00 & & \\
\hline & & \multirow{2}{*}{$\mathrm{F}$} & Athlete & 13 & 11.46 & 149.00 & \multirow{2}{*}{58,000} & \multirow{2}{*}{0.434} \\
\hline & & & Skier & 11 & 13.73 & 151.00 & & \\
\hline
\end{tabular}

Note. ${ }^{*} p<0.05$.

Table 5

Results of Mann Whitney U Test Conducted to Determine the Significance of the Difference Between Gripping Power of Athletes and Skiers

\begin{tabular}{|c|c|c|c|c|c|c|c|c|}
\hline & & Gender & Branş & $N$ & Mean rank & Sum of rank & $U$ & $p$ \\
\hline \multirow{8}{*}{$\begin{array}{l}\text { Gripping } \\
\text { power }\end{array}$} & \multirow{4}{*}{ Right } & \multirow{2}{*}{ M } & Athlete & 17 & 19.06 & 324.00 & \multirow{2}{*}{67,000} & \multirow{2}{*}{$0.039^{*}$} \\
\hline & & & Skier & 14 & 12.29 & 172.00 & & \\
\hline & & \multirow{2}{*}{ F } & Athlete & 13 & 15.08 & 144.00 & \multirow{2}{*}{53,000} & \multirow{2}{*}{0.284} \\
\hline & & & Skier & 11 & 14.18 & 156.00 & & \\
\hline & \multirow{4}{*}{ Left } & \multirow{2}{*}{ M } & Athlete & 17 & 18.41 & 313.00 & \multirow{2}{*}{78,000} & \multirow{2}{*}{0.173} \\
\hline & & & Skier & 14 & 13.07 & 183.00 & & \\
\hline & & \multirow{2}{*}{$\mathrm{F}$} & Athlete & 13 & 11.15 & 145.00 & \multirow{2}{*}{54,000} & \multirow{2}{*}{0.311} \\
\hline & & & Skier & 11 & 14.09 & 155.00 & & \\
\hline
\end{tabular}

Note. ${ }^{*} p<0.05$.

Table 6

Results of Mann Whitney U Test Conducted to Determine the Significance of the Difference Between Flexibility Values of Athletes and Skiers

\begin{tabular}{llllllll}
\hline & Gender & Branch & $N$ & Mean rank & Sum of rank & $U$ & $p$ \\
\hline \multirow{6}{*}{ Flexibility } & \multirow{2}{*}{$\mathrm{M}$} & Athlete & 17 & 17.91 & 304.50 & \multirow{2}{*}{06,500} & 0.196 \\
& & Skier & 14 & 13.98 & 191.50 & & \multirow{2}{*}{0.885} \\
& & F & Athlete & 13 & 12.69 & 165.00 & \multirow{2}{*}{69,000} \\
\hline
\end{tabular}

Results of Mann Whitney $U$ Test, which was conducted to detect the significance of difference between flexibility of athletes and skiers, are provided in Table 6 . According to Table 6 , it is understood that there are no significant differences between the flexibility values of female and male athletes and skiers $(p>0.05)$. 


\section{Discussions and Conclusions}

Seventeen male athletes competing at international level with an average age of $19.29 \pm 3.35$, height of $175.59 \pm 6.72 \mathrm{~cm}$, weight of $65.78 \pm 9.64 \mathrm{~kg}$, BMI of $21.29 \pm 2.53\left(\mathrm{~kg} / \mathrm{m}^{2}\right)$, and sports experience of $6.65 \pm$ 4.05 years and 13 female athletes competing at international level with an average age of $17.85 \pm 2.67$ years, height of $164.3 \pm 4.95 \mathrm{~cm}$, weight of $53.32 \pm 7.21 \mathrm{~kg}$, BMI of $19.72 \pm 2.14\left(\mathrm{~kg} / \mathrm{m}^{2}\right)$, and sports experience of $4.08 \pm 2.10$ years participated in this research. Breathing parameters, anaerobic capacities, and gripping powers of male and female athletes were determined via body composition analysis. Data provided above were compared with 14 male cross-country skiers competing at international level with an average age of $18.64 \pm$ 3.59 years, height of $174.57 \pm 11.02 \mathrm{~cm}$, weight of $66.02 \pm 17.57 \mathrm{~kg}$, BMI of $21.37 \pm 4.07\left(\mathrm{~kg} / \mathrm{m}^{2}\right)$, and sports experience of $5.93 \pm 3.75$ years and 11 female cross-country skiers competing at international level at an average age of $17.91 \pm 2.84$ years, height of $161.27 \pm 6.05 \mathrm{~cm}$, weight of $57.89 \pm 6.32 \mathrm{~kg}$, BMI of $22.23 \pm 1.86$ $\left(\mathrm{kg} / \mathrm{m}^{2}\right)$, and sports experience of $5.09 \pm 2.95$ years.

When the breathing parameters of sportsmen who participated in this research were evaluated, it was determined that there are no significant differences between breathing values, FVC, FEV1, PEF, FEF2575, VC, $\mathrm{TV}$, and MVV, of female and male athletes and cross-country skiers $(p>0.05)$. However, there are significant statistical differences between breathing values (FEV1/FVC) of female athletes and skiers competing at international level $(p<0.05)$.

In the study on comparison of breathing functions of sportsmen, Kara, Özal, and Yavuz (2010) did not find any significant statistical differences between breathing functions of wrestlers and basketball players from Turkish national teams. In the study on comparison of breathing functions of young team sportsmen from individual sports branches, Atan, Akyol, and Çebi (2013) found that breathing function of professional sportsmen was higher than others. They also found that different breathing functions of sportsmen from different branches might mean that the branch of sports involved statistically affected the overall breathing capacity of the sportsmen. This finding supports our finding "no statistically significant differences between breathing capacity of athletes and skiers" due to the fact that both branches of sports include long-distance running.

The finding of the study, which suggests there are significant differences between FEV1/FVC values of female athletes $(\mathrm{FEV} 1 / \mathrm{FVC}$ average $=15.38)$ and female skiers (FEV1/FVC average $=9.09)$ competing at international level, requires taking into consideration the different components and factors that affect the performance of sportsmen in these tests. Based on the literature research we conducted forting the study, it might be concluded that this difference is based on individiuals' physical differences.

As a result of the test conducted to determine the significance of body composition value differences between athletes and skiers who participated in the research, it is understood that there are significant differences between FW and TBW body composition values of female athletes (FW average $=9.15$ and TBW average $=15.38)$ and female skiers $(\mathrm{FW}$ average $=16.45$ and TBW average $=9.09)(p<0.05)$. According to this result, body fat rate of athletes is higher when compared to that of cross-country skiers, while body fluid rate is lower than that of skiers.

In the study, conducted by Kürkçü, Afyon, Yaman, and Özdağ (2009), on comparison of some physical and physiological attributes of 18 male football players and 12 male badminton players between the ages of $10-12$, it is understood that there are no significant differences between BMI averages of subjects. Fat amount 
in the body is reduced as a result of training which results to high amount of calory burned (Stamford, 1983). Based on this, it might be concluded that the fact that there are no significant differences between body composition values of male athletes and skiers might indicate that body of both sportsmen respond similarly to training and that this might be due to both branches including long-distance running. As a result, it is understood that there are no significant differences between PP, AP, and MP of male and female athletes and skiers $(p>0.05)$.

There are significant differences between physical attributes of male and female individuals in terms of body composition, muscle mass, hormonal balance (Rickenlund et al., 2003) and oxygen consumption (Korhonen, Mero, \& Suominen, 2003). In addition to kin anthropometric attributes, it is widely known that somatotype, which has effects on selection of branches, selection of position, and sports performance, is significantly different in men and women (Gualdi-Russo \& Graziani, 1993).

Today, it is known that productivity of sportsmen is affected by many psychic and physical mechanisms. For that reason, it is more appropriate to interpret the performance of a sportsmen as the result of athletic productivity, production quality, and production capacity of sportsmen with the help of positive and despite negative affects (Bayraktar, 2004; Atasü \& Yücesir, 2004). This definition takes into consideration that sportsmen competing in different branches of sports have different body weight, muscle mass, body mass without fat, body fat, and even body proportion, and it is known that body composition is in positive correlation with performance (Strudwick \& Doran, 2002; Leone, Lariviere, \& Comtois, 2002). Based on these, we might conclude that sportsmen competing in similar branches of sports have similar body weight, height, muscle mass, body mass without fat, body fat, and even body proportion, and we might further conclude that this finding is parallel to findings of our study. Rock climbers have lower weight and much lower body fat rate when compared with sportsmen from other branches of sports, whereas elite swimmers, athletes, basketball and football players have different non-fat body mass and body fat rate despite the fact that they have similar body mass index values (Watts, Joubert, Lish, Mast, \& Wilkins, 2003). Studies on football, which is the most popular sports in the world, indicate that antropometric and physiological attributes significantly affect positions, talents, and training responses of football players (Reilly, Williams, Nevill, \& Franks, 2000; Reilly, Bangsbo, \& Franks, 2000). In addition, it is an undeniable fact that different branches of sports might be successfully executed by sportsmen with different antropometric attributes.

There are no significant differences between right hand and left hand gripping powers of female athletes and skiers $(p>0.05)$, while there are significant difference between right hand grippipng powers of male athletes $($ mean $=19.06)$ and skiers $($ mean $=12.29)(p<0.05)$.

In a study conducted by Çınar (2009), on some physical parameters of elite female boxers and handball players, it was claimed that there were no significant differences between left hand gripping powers of sportsmen $(p>0.05)$, while there were significant differences between right hand gripping powers in favor of handball players $(p<0.05)$. In a study conducted by Savaş and Uğraş in 2004, it was understood that the differences between right hand and left hand gripping powers of boxers, karate athletes, and taekwondo athletes were not significantly different. In a study conducted by Aydos, Pepe, and Karakuş in 2004, it was understood that left hand gripping powers of sportsmen from different branches were similar and this supports the findings of our study.

Average flexibility of female athletes who participated in the study is mean $=12.69$, whereas the flexibility value of female cross-country skiers is mean $=12.27$. In the same study, average flexibility value of 
male athletes is mean $=17.91$, whereas male cross-country skiers' average flexibility value is mean $=13.98$. As a result of the analysis performed, there are no significant differences between flexibility values of female and male athletes and cross-country skiers $(p>0.05)$.

Özer and Kılınç (2012) studied and found that flexibility of male individual sportsmen was $34.3 \pm 9.7 \mathrm{~cm}$ and flexibility of male team sports members was $24.5 \pm 6.0 \mathrm{~cm}$, and that such difference in average flexilibity values was considered significantly different $(p<0.05)$. In a study conducted by Koç, Özcan, Pulur, and Ayaz (2007), average flexibility value of handball players was $20.8 \pm 5.1 \mathrm{~cm}$, whereas average flexibility value of volleyball players was $8.3 \pm 5.5 \mathrm{~cm}$. In a study of Çelenk and Çumralıgil (2005) on comparison of some physical and physiological attributes of individual sportsmen and team sport members, it was found that the torso flexibility of volleyball players was $14.80 \pm 5.0 \mathrm{~cm}$; football players' flexibility was $17.78 \pm 3.43 \mathrm{~cm}$; taekwondo athletes' flexibility was $36.62 \pm 9.01 \mathrm{~cm}$; and Judo athletes' flexibility was $35.55 \pm 7.22$. As a result of group comparison of data collected from individual sportsmen and team sports members, it was understood that there were significant differences between torso flexibility of individual sportsmen and team sports members, in favor of individual sportsmen $(p<0.01)$. Average values found in literature researches support the findings of our study.

As a result, when physical and physiological attributes of female and male athletes and skiers are compared, it was understood that FEV1/FVC breathing parameters and FW and TBW (\%) body composition values of female athletes and skiers are significantly different, so are the right hand and left hand gripping powers of male athletes and skiers. In this context, it might be concluded that there are no significant differences among sportsmen who participate in branches of sports which are similar to each other (long-distance running, individual sports, etc.) and which utilize same energy systems in the body.

\section{References}

Alpay, B., Altuğ, K., \& Hazar, S. (2007). Comparison of some respiration and circulatory parameters of students aged 11-13 in school teams with those of students who don't do sports. Mehmet Akif Ersoy University Journal of Education Faculty, 8(17), 22-29.

Atan, T., Akyol, P., \& Çebi, M. (2013). Comparison of respiratory functions of athletes engaged in different individual sports branches. Dicle Medical Journal, 40(2).

Atasü, T., \& Yücesir, İ. (2004). Doping and performance improving methods in football (pp. 269-296). Istanbul: Turkish Football Federation Publications. Retrieved from https://www.tff.org/Resources/TFF/Documents/TFF/DopingleMucadeleKurulu/ DOPING-VE-PERFORMANS-ARTIRMA-YONTEMLERI.pdf

Aydos, L., Pepe, H., \& Karakuş, H. (2004). The research of relative force evaluations in some team and individual sports. Ahi Evran University Journal of Kirşehir Education Faculty, 5(2).

Bayraktar, B., Kurtoğlu, M. (2004). Performance in sports and performance iımproving methods. In T. Atasü, \& İ. Yücesir (Eds.), Doping and performance improving methods in football (pp.269-296). İstanbul: Turkish Football Federation Publications.

Bayraktar, I., Deliceoğlu, G., Yaman, M., \& Yaman, Ç. (2012). The comparison of some physical and physiological parameters of sprinters and throwers with same age wrestlers. International Refereed Academic Journal of Health and Medical Sciences, 2(2), 37-46.

Büyüköztürk, Ş. (2009). Data analysis handbook for social sciences: Statistics, research design, SPSS applications and comments (9th ed.). Ankara: Pegem Publications.

Çelenk, Ç., \& Çumralıgil, B. (2005). Comparison some physical and physiological pecularities of individual sporters and team sporters. Journal of Physical Education and Sport Sciences, 7(3).

Çetin, E. (2002). A comparison the effects of eight weeks roller ski and running endurance training programs on maxvo2 and other physiological parameters of 13-16 year age group cross-country skiers. Ankara: Department of Physical Education and Sports, Institute of Health Sciences, Gazi University. 
Çınar, M. T. (2009). 21-Day fat burning. Monthly Fitness Magzine. Retrieved Octomber 25, 2016, from https://play.google.com/books/reader?id=XLCECgAAQBAJ\&printsec=frontcover\&output=reader\&hl=tr\&pg=GBS.PA1

Fox, E. L., \& Mathews, D. K. (1976). The pyhsiological basis of physical education and athletics (pp. 218-219). New York: Saunders.

Gökbel, H., Çalışkan, S., Özbay, Y., \& Bediz, C. Ş. (1993). The anaerobic power values in wingate tests with two different loads. Journal of Sport Sciences, 4(4), 10-16.

Gualdi-Russo, E., \& Graziani, I. (1993). Anthropometric somatotype of Italian sport participants. The Journal of Sports Medicine and Physical Fitness, 33(3), 282-291.

Inbar, O., Bar-Or, O., \& Skinner, J. S. (1996). The Wingate anaerobic test: Development, characteristics, and application. Champaign, I.L.: Human Kinetics.

Kara, E., Özal, M., \& Yavuz, H. U. (2010). Comparison of the blood parameters and respiratory functions of elite wrestlers and basketball players. Selçuk University Journal of Physical Education and Sport Science, 12(1), 36-41.

Karakaş, F. (2012). An investigation of the relationship between multiple reaction time and isokinetic balance (Master's thesis, Ondokuz Mayıs University).

Koç, H., Özcan, K., Pulur, A., \& Ayaz, A. (2007). Comparison of some physical and physiological parameters of elite woman handball and voleyball players. Spormetre Journal of Physical Education and Sports Sciences, 3, 123-128.

Korhonen, M. T., Mero, A., \& Suominen, H. (2003). Age-related differences in 100m sprint performance in male and female master runners. Medicine and Science in Sports and Exercise, 35(8), 1419-1428.

Köklü, Y., Özkan, A., Alemdaroğlu, U., \& Ersöz, G. (2009). The comparison of some physical fitness and somatotype characteristics of young soccer players according to their playing positions. Spormetre Journal of Physical Education and Sports Sciences, 7(2), 61-68.

Kürkçü, R., \& Gökhan, İ. (2011). The effects of handball training on the some respiration and circulatory parameters of school boys aged 10-13 years. International Journal of Human Sciences, 8(1), 135-143.

Kürkçü, R., Afyon, Y. A., Yaman, Ç., \& Özdağ, S. (2009). Comparison of some physical and physiologic properties of soccer players and badminton players of 10-12 years old group. International Journal of Human Sciences, 6(1), 547-556.

Leone, M., Lariviere, G., \& Comtois, A. S. (2002). Discriminant analysis of anthropometric and biomotor variables among elite adolescent female athletes in four sports. Journal of Sports Sciences, 20(6), 443-449.

Norris, J. M. et al. (2005). Quantitative trait loci for abdominal fat and BMI in Hispanic-Americans and African-Americans: The IRAS family study. International Journal of Obesity, 29(1), 67-77.

Norstrud, H. (2008). Cross-country skiing, in CSIM international centre for mechanical sciences. New York: Springer Wien Publications.

Öncü, İ. (2009). The relationship between diet, exercise, and metabolic parameters in childhood obesity (Dissertation, Çukurova University).

Özer, Ö., \& Kılınç, F. (2012). Elite athletes in individual and team strength, speed, and flexibility to compare their performance. Journal of Human Sciences, 9(1), 360-371.

Reilly, T., Bangsbo, J., \& Franks, A. (2000). Anthropometric and physiological predispositions for elite soccer. Journal of Sports Sciences, 18(9), 669-683.

Reilly, T., Williams, A. M., Nevill, A., \& Franks, A. (2000). A multidisciplinary approach to talent identification in soccer. Journal of Sports Sciences, 18(9), 695-702.

Rickenlund, A. et al. (2003). Hyper androgenicity is an alternative mechanism underlying oligomenorrhea or amenorrhea in female athletes and may improve physical performance. Fertility and Sterility, 79(4), 947-955.

Rusko, H. (2003). Physiology of cross-country skiing. In H. Rusko (Ed.), Cross-country skiing. USA, M.A.: Blackwell Science.

Savaş, S., \& Uğraş, A. (2004). Effects of eight-week pre-season training program on some physical and physiological characteristics of collegiate male box, taekwondo and karate players. Gazi University Journal of Education Faculty, 24(3).

Savucu, Y., Çınar, V., \& Polat, Y. (2009). Investigation on some physical parameters of elite female boxing and handball players. Sport Sciences, 4(3), 171-178.

Savucu, Y., Polat, Y., Bicer, Y. S. (2005). The effects of athleticism training which is applied with and without games for 12 weeks for athletic children on physical suitability. Journal of Medicine Sciences, 19(3), 199-204.

Sifill, A. et al. (2001). The comparison of dual-energy x-ray absorbtiometry and bioelectric impedance analysis in determination of body composition in hemodailysis patients. Official Journal of the Turkish Society of Nephrology, 10(4), 244-248.

Spring, V. (2002). Cross-country ski trails in Washington (3rd ed.). USA: The Mountainers Books. 
Stamford, B. (1983). The results of aerobic exercise. The Physician and Sports Medicine, 11(9), 145.

Stöggl, T., Enqvist, J., Müller, E., \& Holmberg, H. C. (2010). Relationships between body composition, body dimensions, and peak speed in cross-country sprint skiing. Journal of Sports Sciences, 28(2), 161-169.

Strudwick, A., \& Doran, T. R. D. (2002). Anthropometric and fitness profiles of elite players in two football codes. Journal of Sports Medicine and Physical Fitness, 42(2), 239.

Şahin, M. (2011). Evaluation of some physical and physiologic parameters of Alpine ski trainers. International Refereed Journal of Academic Social Sciences, 1, 108-113.

Tanner, R., \& Gore, C. (2013). Physiological tests for elite athletes. Champaign, I.L.: Human Kinetics.

Url. (2016). Body composition analysis: User's guide for bodystat 1500. U.K.: Bodystat Ltd.. Retrieved January 2, 2016, from http://www.bodystat.com/pdf/spreads/1500.pdf

Watts, P. B., Joubert, L., Lish, A. K., Mast, J. D., \& Wilkins, B. (2003). Anthropometry of young competitive sport rock climbers. British Journal of Sports Medicine, 37(5), 420-424. 